\title{
Práticas e Reflexões Sobre a Aprendizagem Colaborativa e Uso do Tablet no Contexto Escolar
}

\author{
Practices and Reflections on Collaborative Learning \\ and Tablet Use in School Context
}

\author{
ANA PAULA KNAUL \\ Universidade Federal de Santa Catarina \\ DANIELA KARINE RAMOS \\ Universidade Federal de Santa Catarina
}

\begin{abstract}
Resumo: A colaboração pode transformar os espaços sociais e contribuir com a formação integral dos alunos; o que se contrapõe ao isolamento e pouca interação que o uso dos tablets pode ocasionar. Diante disso, este estudo tem o objetivo de analisar a aprendizagem colaborativa na integração do uso do tablet nos anos iniciais do Ensino Fundamental. O estudo exploratório e de abordagem qualitativa pautou-se na proposição de intervenções utilizando tablet em duas turmas do $1^{\circ}$ ano e na realização de observações e entrevistas com as crianças e professoras. A partir disso, destacamos que o tipo atividade, a organização do espaço, a interação social e o uso do tablet interferem no nível de colaboração. Por fim, reforçamos que não é o uso da tecnologia que individualiza ou favorece a colaboração, mas sim a combinação entre o planejamento, os objetivos, as estratégias e a mediação pedagógica que contribuem para que ocorram esses processos.
\end{abstract}

Palavras-chave: Práticas pedagógicas. Tablets. aprendizagem colaborativa.

\begin{abstract}
The collaboration can to transform social spaces and to contribute to the integral formation of students; which is opposed to isolation and little interaction that the use of the tablets can cause. Thus, this study aims to analyze collaborative learning in the integration of tablet use in the elementary school. The exploratory and qualitative approach was guided in suggesting interventions using tablets in two classes of the 1st year and in conducting observations and interviews with children and teachers. From this, we point out that the type activity, the organization of space, the social interaction and the use of tablet interfere in the level of collaboration. Finally, we reinforce that it is not the use of technology that individualizes or favors collaboration, but the combination of planning, objectives, strategies and the mediation that contribute to these processes occur.
\end{abstract}

Keywords: Pedagogical practices. Tablets. Collaborative learning. 


\section{Introdução}

Os processos de ensino e de aprendizagem na contemporaneidade ocorrem de forma cada vez mais descentralizada e requerem o desenvolvimento de novos letramentos para a ampliação de repertórios de habilidades e práticas sociais. Aproximações com autores, como Lankshear e Knobel (2006), nos mostram que os letramentos convencionais não são o bastante. Para eles, os "letramentos são as diferentes formas sociais de produção, comunicação e negociação de conteúdos significativos mediados pela codificação de textos dentro de contextos de participação em discursos" (p. 64). Já os novos letramentos, ou new literacies, de acordo com a concepção que fundamentam, objetivam ir além dos letramentos convencionais ou familiares, pois incidem numa direção ontológica, relevando o que é mais significativo das transformações sociais no processo de construção de significados na contemporaneidade. (LANKSHEAR; KNOBEL, 2006, KNOBEL; LANKSHEAR, 2007).

Com as transformações ocorridas nas formas de ler e escrever, devido ao desenvolvimento das tecnologias digitais na contemporaneidade - pelas quais a leitura e a escrita se fazem por meio de telas e teclados -, encontramo-nos diante de letramentos, proporcionados por diferentes meios digitais. (SOARES, 2002). Meios esses que criam novos modos de construir significados e de aprender na cultura da convergência, pois há que se considerar que "as tecnologias de escrita, instrumentos das práticas sociais de leitura e de escrita, desempenham um papel de organização e reorganização desse estado ou condição" (ibid, 2002, p. 148) letrada dos sujeitos.

Portanto, cabe à escola, como um espaço voltado à formação, possibilitar o acesso das crianças às diferentes linguagens presentes nas Tecnologias Digitais de Informação e de Comunicação (TDIC), além de problematizar sobre o seu uso e conteúdo, no intuito de produzir conhecimentos com, para e através das mídias. Essas tecnologias podem ser compreendidas como meios de comunicação, representação e transmissão de informações, as quais caracterizam-se pela velocidade, imediatismo e convergência, combinando diferentes recursos, como textos, imagens, sons, movimentos e interatividade (COLL; MONEREO, 2010).

Um estudo longitudinal realizado por Hatzigianni, Gregoriadis e Fleer (2016), baseado na teoria histórico-cultural, analisou os efeitos do uso de computadores em escolas australianas sobre os aspectos sócio-emocionais das crianças. A pesquisa envolveu uma amostra de 3345 crianças (8-9 anos), considerando dados coletados por meio de uma base de dados das escolas e relatório dos professores, em que os resultados sugeriram que as crianças australianas estão usando computadores para prática de habilidades de aprendizagem específicas (por exemplo, matemática e alfabetização) e, raramente, estão envolvidos em atividades criativas. Além disso, os resultados revelam que o uso geral do computador não parece ter um impacto significativo sobre os resultados sócio-emocional das crianças.

Diante desse resultado e problemática apresentada na pesquisa apontada, buscamos com esse artigo apresentar o que a nossa pesquisa revela em relação ao desenvolvimento de outras aprendizagens e letramentos que podem surgir a partir da mediação com a tecnologia móvel. 
Dentre as TDIC, nosso estudo debruçou-se sobre o uso do tablet, uma tecnologia móvel. A característica de mobilidade por si só pode contribuir para modificar os sentidos e as práticas escolares. Para Rogers e Price (2009), aprender por meio do uso de uma tecnologia móvel motiva as crianças pelo fato delas poderem estar em movimento nesse processo, não tendo necessariamente que ficar paradas. Desse modo, os autores consideram que os usos dessas tecnologias contribuem para o desenvolvimento das crianças, já que elas podem ter acesso a conhecimentos de diferentes maneiras, inclusive, em movimento, bem como podem escolher a sua trajetória de aprendizagem.

Ao realizarem uma revisão de literatura ${ }^{30}$, Rogers e Price (2008) constataram três contribuições da aprendizagem móvel com relação àquela realizada em PC. Primeiramente, temos a presença de um elemento motivacional à aprendizagem das crianças no uso da tecnologia móvel, que é possibilidade de integração entre uma atividade física e uma tarefa desconhecida a ser desempenhada com o uso desses suportes, para a descoberta de informações e progresso através de suas próprias ações físicas. A "combinação entre atividades físicas e mentais é destinada a aprimorar as habilidades motoras, de reconhecimento de padrões, ritmo e coordenação". (ROGERS; PRICE, 2009, p. 6).

Como segundo aspecto relevante, temos o incentivo para o uso desse tipo de tecnologia, pelas crianças, devido à mobilidade que ela oferece, proporcionando a realização de diferentes práticas sociais e processos cognitivos. Acrescentamos que esta possibilidade permite que essas tecnologias sejam utilizadas em sala de aula, de forma mais integrada às próprias rotinas escolares, sem a necessidade de ter que deslocar todo grupo a um laboratório de informática. E, por fim, as autoras citam que as diferentes maneiras de acesso a tecnologia - que incluem as estratégias pedagógicas planejadas e o uso, seja ele em movimento ou sobre uma mesa permitem às crianças maior integração dos seus conhecimentos prévios com a realização de atividades.

Outra consequência do uso dos tablets em sala que pode ser levantada é que favorece um maior isolamento e pouca interação social, devido a motivação para o uso e a imersão dos alunos na manipulação do dispositivo. Em suas pesquisas, Rogers e Price (2009) afirmam que a manipulação da tecnologia móvel tende a individualizar as relações sociais, bem como consideram que a sobrecarga de informações pode gerar distração ao usuário.

Por outro lado, a colaboração frequentemente é apontada por seu potencial para transformar os espaços sociais e contribuir com a formaçãointegral dos alunos, o que se contrapõe ao isolamento e a pouca interação. Como podemos observar no estudo de Fallon (2015) que analisou o uso de IPads como parte de ambientes de sala de aula regular, a partir dos dados coletados ao longo de quase três anos com 100 crianças dos primeiros alunos da Ensino Fundamental da Nova Zelândia, procurando diferentes fontes de dados para explorar como atributos de design de dispositivos e aplicativos observados e registrados, o autor revela que esses suportes afetavam a capacidade dos alunos para trabalhar de forma colaborativa. Os

30 Dentre as pesquisas sobre o uso de tecnologia móvel para aprendizagem, encontradas por Rogers e Price (2009) citamos a de Moher, Hussain, Halter e Kilb (2005), que aborda a simulação de fenômenos naturais com o uso do aplicativo RoomQuake. Com esse programa as crianças observam como acontecem os eventos sísmicos através de uma simulação autêntica dos mesmos, fazendo a medição do fenômeno, dentre outros processos de investigação. 
resultados sugerem que existem diferenças fundamentais entre iPads e outros dispositivos digitais que ajudaram estes alunos a colaborarem, e que, quando combinado com aplicativos e serviços baseados na nuvem, como o Google Docs, pode-se ampliar as possibilidades de colaboração entre as pessoas para além da escola.

Outra questão que também nos problematiza ao pensar na integração de uma tecnologia móvel na escola e em seus processos educativos é a de que Turkle (2011) aponta, ao dizer que o fato de estarmos online por meio de uma tecnologia móvel significa estarmos presentes uns com os outros, e ao mesmo tempo isolados, sendo essa uma pré-condição para que essa interação online ocorra. Em nossa pesquisa o fato de as crianças estarem reunidas no coletivo da escola contrapõe-se ao isolamento, incentivando a interação social no uso da tecnologia móvel.

Diante disso, o nosso estudo tem o objetivo de analisar a aprendizagem colaborativa na integração do uso do tablet aos processos de ensino e aprendizagem de crianças dos anos iniciais do Ensino Fundamental.

\section{Estratégias pedagógicas para produção de novos letramentos: colaboração e o uso dos tablets}

Partindo da perspectiva de que "ninguém educa ninguém, ninguém se educa a si mesmo, os homens se educam entre si, mediatizados pelo mundo" (FREIRE, 1981, p. 79), revisitamos a concepção de Vigotski (1991), que considera que o aprendizado ocorre por meio da interação social, para refletirmos sobre como a colaboração pode ser uma estratégia para a promoção de novos letramentos por meio das tecnologias móveis.

O princípio da colaboração, segundo Rosatelli, Souza e Arriada (2003), consiste numa situação de aprendizagem coletiva entre dois ou mais sujeitos. Partindo desse pressuposto, utilizamos esse conceito como estratégia pedagógica para o desenvolvimento de novos letramentos, o que resultou em diferentes processos de aprendizagem colaborativa entre as crianças.

Com base em seus estudos, Ramos (2005, p. 50) afirma que a colaboração consiste em um "movimento de interação entre indivíduos para a produção e construção de saberes, habilidades e sentidos. Este processo supõe a interação entre dois ou mais indivíduos; um ambiente que viabilize e possibilite a comunicação; e orientações ou regras para organizar o desenvolvimento da atividade".

Nesse sentido, destacamos que a colaboração pressupõe algumas condições para sua efetivação, incluindo questões relacionadas as práticas pedagógicas, seus sujeitos, recursos e organização com vistas a alcançar objetivos. Na colaboração a interação social e a aprendizagem ganham ênfase por envolver "uma situação na qual duas ou mais pessoas aprendem ou tentam aprender algo juntas" (ROSATELLI et al, 2003, p.49). Esse processo de interação com o outro contribui para desenvolver um caráter voluntário e consciente dos sujeitos com relação à colaboração, pois "pôr-se de acordo acerca de uma solução comum exige comunicar ao outro o seu próprio procedimento, eventualmente situá-lo em relação ao do parceiro, ou até mesmo argumentar contra o projeto de seu parceiro" (LABORDE, 1996, p. 42). 
O desafio de nosso estudo era contribuir para a criação de situações de interação entre os sujeitos com e por meio de tablets para promover o desenvolvimento de novos letramentos e, inclusive, para a promoção da aprendizagem colaborativa. A partir da delimitação dos objetivos de aprendizagem e das estratégias pedagógicas traçadas para alcançá-los, os educadores podem estabelecer como prerrogativa a necessidade dos(as) alunos(as) compartilharem informações, conhecimentos e experiências para avançar no processo de aprendizagem.

Desse modo, os alunos podem aprender a conversar com o outro, estruturar a fala para socializar suas ideias, bem como perceber a contribuição do(a) colega e valorizar a sua participação na construção de um projeto comum, aproximando-se em maior ou menor nível de aprendizagem colaborativa.

Brna (1998, apud RAMOS, 2005, p.51) apresenta seis níveis de colaboração que caracterizam a aprendizagem colaborativa, como se pode observar na tabela 1 abaixo:

Tabela 1. Níveis de Colaboração.

\begin{tabular}{|c|c|}
\hline Divisão de trabalho & $\begin{array}{l}\text { O trabalho é dividido em tarefas e cada membro do } \\
\text { grupo fica responsável por uma delas. }\end{array}$ \\
\hline Estado de colaboração & $\begin{array}{c}\text { Há momentos de trabalho individual e momentos de } \\
\text { trabalho em grupo. }\end{array}$ \\
\hline $\begin{array}{l}\text { Colaboração como } \\
\text { propósito final }\end{array}$ & $\begin{array}{l}\text { O trabalho tem como objetivo o aprender a } \\
\text { colaborar. }\end{array}$ \\
\hline Colaboração como meio & $\begin{array}{l}\text { O objetivo do trabalho é aprender algo a partir de } \\
\text { ações colaborativas. }\end{array}$ \\
\hline Colaboração formal & $\begin{array}{l}\text { Os membros do grupo se comprometem e firmam } \\
\text { acordo para realizar o trabalho colaborativamente. }\end{array}$ \\
\hline Colaboração informal & A colaboração surge espontaneamente. \\
\hline
\end{tabular}

Fonte: Adaptado de Brna (1998, apud Ramos, 2005, p.51).

Com base nos modelos sistematizados por Brna (1998), que representam um processo ou estado de aprendizagem colaborativa, consideramos que as estratégias didáticas pensadas para a realização das práticas pedagógicas podem contribuir para tal fim ao serem intencionadas nessa direção.

Pensando nisso, citamos o exemplo do projeto Ambient Wood que, de acordo com Rogers et. al. (2004, apud ROGERS e PRICE, 2009), teve como objetivo realizar uma visita de campo com crianças entre 10 e 12 anos para explorar uma floresta, contando com a utilização de uma 
tecnologia móvel, um palmtop. No entanto, durante essa proposta, foi observado que as crianças poderiam isolar-se no uso dessas tecnologias em atividades.

Assim, tendo em vista a importância da interação social no desenvolvimento de aprendizagens e deparando-se com alguns casos que demonstram que a tecnologia móvel pode proporcionar a individualidade,

[...] alguns podem supor que a imersão em tecnologias móveis seria prejudicial para o desenvolvimento dessas habilidades. Eles podem imaginar uma criança solitária, sozinha em seu quarto e focado apenas em seu telefone celular, ou uma sala de aula de crianças sentadas calmamente em suas mesas, cabeças enterradas em pequenas telas individuais. (CHING et. al., 2009, p. 25).

Pautadas nessa problemática, Rogers e Price (2009) fizeram com que as crianças tivessem que colaborar e interagir umas com as outras para progredir na sua tarefa, propondo que cada uma assumisse uma função e ficasse responsável por transmitir certas informações aos colegas em determinados momentos da proposta. Nesse contexto, o papel do educador foi o de mediador, contribuindo com orientações, pistas, feedbacks quando julgasse necessário.

Além da possível individualidade causada pela manipulação dessas tecnologias, Rogers e Price (2009) citam a sobrecarga de informações e a distração como desafios a serem enfrentados na interação das crianças com as tecnologias móveis.

Levando em conta os desafios citados, as autoras indicam que sejam propostas atividades físicas por meio das tecnologias móveis durante as tarefas de cunho exploratório, pois, assim, as crianças conseguem perceber o efeito de suas ações, criando representações abstratas para a construção do conhecimento conceitual.

A participação em atividades de simulação contribui para que as crianças possam trabalhar coletivamente e notar, com isso, o efeito das ações conjuntas. Com as atividades de criação de conteúdo as crianças aprendem a desenvolver narrativas e a se manifestarem por meio de diferentes formas de representação. (ROGERS e PRICE, 2009).

Outra questão muito importante é a possibilidade de a criança estabelecer relações do mundo virtual com os seus conhecimentos prévios, tornando o aprendizado ainda mais significativo para a sua compreensão da realidade.

Assim sendo, percebemos que o uso da tecnologia móvel em uma atividade de aprendizagem pode tornar-se um facilitador das interações colaborativas entre as crianças, pois "através de dispositivos móveis, as crianças têm melhorado as maneiras de formar as suas próprias redes de aprendizagem se comunicando com seus pares e professores por meio de conversas, mensagens de texto, e-mail e redes sociais". (FIELD, 2005 apud CHING et. al, 2009, p. 26-27).

A mobilidade não pode ser vista apenas pela possibilidade de aprender a qualquer hora e em qualquer lugar, mas como potencialidade para estabelecer relações junto aos outros. (ROGERS; PRICE, 2009). Nesse sentido, um desafio importante aos educadores no ambiente escolar, ainda segundo os autores, é o de realizar mediações constantes para que a criança consiga alternar a sua atenção em atividades tanto físicas como digitais em consonância com as interações sociais, necessárias ao aprendizado. 
Enfatizamos isso por considerarmos a importância de atividades que priorizem o alcance da Zona de Desenvolvimento Proximal da criança, que é "determinado através da solução de problemas sob a orientação de um adulto ou em colaboração com companheiros mais capazes" (VIGOTSKI, 1991, p. 97).

Dessa forma, destacamos que concernem às práticas pedagógicas estimular o desenvolvimento da aprendizagem colaborativa pelas crianças no uso desses meios, com a produção de conteúdos em colaboração com os pares e experiências diversas a partir do uso de jogos eletrônicos, por exemplo, relacionando situações reais com aquelas simuladas pelos ambientes virtuais. (SHORE, 2008)

Para tanto, ainda existem muitas preocupações e desafios a serem enfrentados com relação à integração da tecnologia móvel aos processos de ensino e aprendizagem escolares, conforme apresentaremos a seguir, tendo em vista a recente inserção desses meios nas escolas e a necessidade de pesquisas aprofundando essa temática.

\section{Metodologia}

O estudo desenvolvido caracterizou-se como exploratório, por procurar ampliar a compreensão sobre o tema, explicitando aspectos da situação investigada (MALHEIROS, 2011) e utilizou uma abordagem qualitativa, pautando-se, principalmente, na observação participante e na análise descritiva, partindo da noção da realidade como algo dinâmico e voltando-se para o ambiente natural, a partir do qual são extraídos os dados para análise (GODOY, 1995).

\subsection{Participantes}

O estudo foi realizado com duas turmas do $1^{0}$ ano do ensino fundamental, envolvendo 39 crianças e duas professoras, do Colégio de Aplicação da Universidade Federal de Santa Catarina.

As crianças que participaram da pesquisa tinham entre seis ou sete anos de idade, totalizando 39 crianças, sendo: 20 delas pertencentes de uma turma e 19 de outra. Desse total de crianças, $36 \%$ delas frequentaram a creche desde 0 ou 1 ano de idade, 56\% a frequentaram desde os 2 ou 3 anos de idade e $8 \%$ desde os 5 ou 6 anos de idade. Assim, podemos perceber que a maioria das crianças que participaram da pesquisa já frequenta a educação formal há alguns anos.

Considerando o envolvimento dos sujeitos da pesquisa, a mesma foi submetida para apreciação do Comitê de Ética da Universidade Federal de Santa Catarina e foi aprovada conforme parecer consubstanciado sob o n 875.844 de 2014.

\subsection{Instrumentos e procedimentos}

A pesquisa pautou-se fundamentalmente na observação participante (SCHWARTZ e SCHWARTZ, 1955; COHN, 2005) e seu registro e na proposição de intervenções pautadas na utilização de tablets. A partir disso, crianças e professoras foram entrevistadas sobre o processo realizado. 
As observações privilegiaram a atuação das crianças como sujeitos produtores de cultura, para suas interações em sala de aula com os colegas de turma e com as professoras nos momentos de realização das práticas educativas. Como forma de registro foi utilizado o diário de campo, o qual se compôs por anotações referentes a: verbalizações, interações sociais, manipulação dos recursos, expressões faciais e corporais, bem como comportamentos indicativos de sentimentos das crianças no contexto escolar.

O planejamento das práticas com os tablets foi realizado em conjunto com as duas professoras das turmas, que contribuíram indicando estratégias e dialogando sobre o perfil das crianças e seus conhecimentos prévios.

Tabela 2. Sistematização das intervenções realizadas utilizando os tablets.

\begin{tabular}{|c|c|c|}
\hline INTERVENÇÃO & OBJETIVOS DA INTERVENÇÂO & CONTEÚDOS E PROCEDIMENTOS \\
\hline $\begin{array}{c}1^{\text {a }} \text { Intervenção: } \\
\text { Mobilização por meio de } \\
\text { jogos eletrônicos na } \\
\text { aprendizagem da língua } \\
\text { escrita. }\end{array}$ & $\begin{array}{l}\text { - Promover um momento de ambientação das } \\
\text { crianças com a tecnologia móvel, o tablet. } \\
\text { - Observar como ocorrem os processos de } \\
\text { colaboração na interação entre as crianças com o } \\
\text { uso da tecnologia móvel. } \\
\text { - Trabalhar no desenvolvimento da escrita e leitura } \\
\text { das crianças a partir do uso do jogo eletrônico; } \\
\text { - Problematizar com as crianças questões referentes } \\
\text { a vida dos pinguins, no intuito de estimulá-las a ter } \\
\text { curiosidade no assunto e a desenvolver um olhar } \\
\text { crítico sobre os elementos que pertencem a vida dos } \\
\text { pinguins e ao que se refere somente ao ambiente do } \\
\text { jogo. } \\
\text { - Valorizar as narrativas das crianças, } \\
\text { possibilitando-Ihes vez e voz para representarem as } \\
\text { suas interpretações. }\end{array}$ & $\begin{array}{l}\text { - Uso do aplicativo do jogo "Alfabeto } \\
\text { Melado". } \\
\text { - Uso do aplicativo do jogo } \\
\text { "PororoPenguinRun". } \\
\text { - Socialização com escrita no quadro } \\
\text { dos elementos encontrados no jogo } \\
\text { do Pinguim Pororo. } \\
\text { - Escolha e escrita por meio do } \\
\text { tablet de duas palavras relacionadas } \\
\text { a vida dos pinguins em um } \\
\text { formulário de texto online. }\end{array}$ \\
\hline $\begin{array}{l}2^{\text {a }} \text { Intervenção: } \\
\text { Ampliando o repertório } \\
\text { cultural das crianças na } \\
\text { apresentação de vídeos } \\
\text { pelo tablet. }\end{array}$ & $\begin{array}{c}\text { - Ampliar o repertório cultural das crianças através } \\
\text { da utilização de ferramentas multimídia; } \\
\text { - Observar como as crianças constroem significados } \\
\text { e desenvolvem as suas narrativas a partir da } \\
\text { ampliação de repertórios por meio de imagens } \\
\text { estáticas (fotografias) e movimento (vídeos). } \\
\text { - Explorar a diferentes formas de expressão e } \\
\text { representação por meio da linguagem oral e da } \\
\text { produção escrita. }\end{array}$ & $\begin{array}{c}\text { - Acesso aos vídeos "Pinguim de } \\
\text { Adélia", "Pinguim de Magalhães" e } \\
\text { "Pinguim rei". } \\
\text { - Classificação no quadro das } \\
\text { palavras-chaves relacionadas ao } \\
\text { habitat, características físicas, } \\
\text { alimentação e reprodução dos } \\
\text { pinguins. } \\
\text { - Postagem de comentários no blog } \\
\text { "A vida dos Pinguins", disponível } \\
\text { em: www.tinyurl.com/blog1anobc }\end{array}$ \\
\hline
\end{tabular}




\begin{tabular}{|c|c|c|}
\hline $\begin{array}{l}3^{a} \text { Intervenção: } \\
\text { Explorando diferentes } \\
\text { formas de } \\
\text { representação por meio } \\
\text { da produção } \\
\text { audiovisual. }\end{array}$ & $\begin{array}{l}\text { - Sintetizar o aprendizado construído até o } \\
\text { momento sobre a vida dos pinguins; } \\
\text { - Explorar as diferentes formas de representação } \\
\text { dos significados das crianças e de liberdade de } \\
\text { expressão através de múltiplas linguagens: escrita, } \\
\text { oral, visual, auditiva, tátil, gestual e espacial. } \\
\text { - Possibilitar espaços de autoria das crianças } \\
\text { durante o processo de construção de conhecimentos } \\
\text { e de produção cultural na escola. } \\
\text { - Propor momentos coletivos de interação com jogos } \\
\text { eletrônicos pedagógicos e de entretenimento. }\end{array}$ & $\begin{array}{c}\text { - Produção coletiva em grupo de } \\
\text { desenho em cartaz sobre um dos } \\
\text { aspectos da vida do pinguim, } \\
\text { podendo ser: habitat, características } \\
\text { físicas, alimentação e reprodução. } \\
\text { - Apresentação dos cartazes por } \\
\text { meio de vídeo. } \\
\text { - Filmagem das apresentações pelas } \\
\text { crianças. } \\
\text { - Registro das apresentações por } \\
\text { meio de fotografias tiradas pelo } \\
\text { próprio grupo. } \\
\text { - Uso dos aplicativos: jogo "Monta } \\
\text { palavras" e jogo "Penguim Pile". }\end{array}$ \\
\hline $\begin{array}{l}4^{\text {a }} \text { Intervenção: } \\
\text { Apresentando a vídeo- } \\
\text { carta "A vida dos } \\
\text { pinguins" (Trabalho com } \\
\text { as duas turmas juntas). }\end{array}$ & $\begin{array}{l}\text { - Retribuir às crianças, professoras, escola e pais, } \\
\text { reflexões e imagens de todo o processo } \\
\text { desenvolvido com as crianças, com o auxílio das } \\
\text { professoras e pesquisadora no projeto "A vida dos } \\
\text { pinguins". } \\
\text { - Apresentar conjuntamente as turmas do } 1^{0} \text { ano B } \\
\text { e C a vídeo-carta sobre a vida dos pinguins } \\
\text { produzida pelas próprias crianças. } \\
\text { - Avaliar juntamente as crianças o processo de } \\
\text { ensino e de aprendizagem a partir da integração da } \\
\text { tecnologia móvel nas práticas pedagógicas. }\end{array}$ & $\begin{array}{l}\text { - Apresentação da vídeo-carta } \\
\text { gravada pelas crianças por meio do } \\
\text { projetor multimídia às duas turmas } \\
\text { juntas. }\end{array}$ \\
\hline
\end{tabular}

Fonte: Elaboração das autoras, 2015.

Para registro das práticas pedagógicas realizadas com as turmas utilizou-se duas câmeras filmadoras, localizadas na frente e na lateral da sala, no intuito de captar todas as manifestações das crianças, inclusive, aquelas que não seriam possíveis registrar no diário de campo durante a realização das intervenções.

No sentido de fazer uma avaliação final, junto às crianças, de todas as práticas pedagógicas com o tablet, realizamos uma entrevista em grupo com o intuito de obter informações, por meio de suas narrativas, sobre o que aprenderam e significaram a partir das práticas realizadas. Este tipo de entrevista considera que "[...] na situação grupal, a partilha e o contraste de experiências constrói um quadro de interesses e preocupações comuns que, em parte experienciadas por todos, são raramente articuladas por um único indivíduo" (GASKELL, 2013, p. 77).

Além disso, propusemos uma entrevista individual com cada uma das professoras no intuito de fazer uma avaliação sobre as intervenções, considerando suas impressões sobre o uso da tecnologia móvel no desenvolvimento de novos letramentos pelas crianças, como também de 
levantar aspectos que representassem de que modo estas práticas com o tablet poderiam contribuir para uma reflexão e possível transformação do saber fazer docente nos anos iniciais.

Ambas as entrevistas, com crianças e professoras, em grupo e individuais, foram registradas por meio de gravação de vídeo, com a captura da imagem e do áudio dos sujeitos, além de contar com registro por escrito em diário de campo.

A análise dos dados coletados inspirou na análise de conteúdo descrita por Bardin (1977), utilizando procedimentos sistemáticos de descrição e análise do conteúdo das entrevistas e observações. A partir da leitura flutuante, da seleção de indicadores e da definição das categorias foi possível ampliar a compreensão sobre o uso dos tablets e a aprendizagem colaborativa.

\section{Resultados e discussão}

A sala de aula constitui-se como um contexto social importante para abordar os conteúdos de aprendizagem atitudinais (ZABALA, 1998). Diante disso, reforçamos o papel da escola como um ambiente social que favorece a interação social e permite promover a aprendizagem colaborativa entre as crianças. Entretanto, este tipo de aprendizagem revelou-se um grande desafio nesta pesquisa, especialmente pela delicada tarefa de integrar o tablet como mediador das relações e como suporte da aprendizagem.

Como tema gerador que emergiu do contexto educacional das crianças inseridas no $1^{\circ}$ ano de Ensino Fundamental, a vida dos pingüins destacou-se como um aspecto de grande curiosidade pelas crianças, e foi a partir desse tema que os conteúdos e estratégias pedagógicas foram pensadas, paralelamente ao processo de alfabetização e letramento que já vinha sendo desenvolvido.

Na primeira intervenção, ao realizar a atividade com o jogo Alfabeto Melado ${ }^{31}$, presenciamos o estabelecimento de negociações entre as crianças com relação à vez de jogar, tendo em vista que jogaram em duplas, compartilhando o uso do tablet, aguardando o momento para jogar, muitas vezes estabelecendo as regras e negociando: "'Eu faço a letra $C$ e você a $D$ " disse Pica-

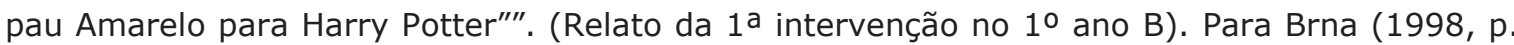
$12), "[\ldots]$ essas questões podem facilmente ser estimuladas em contextos de sala de aula onde se espera frequentemente que as crianças entrem em estado colaborativo em relação às ordens dadas pelo professor".

Durante a situação relatada, percebemos que, além de as crianças dividirem a tarefa de jogar nas duplas em um tablet (1:2), elas comentavam uma com a outra sobre os objetos que apareciam na tela ao traçar as letras, tendo em vista que "em toda colaboração ser humanohumano, todas as partes têm seus próprios objetivos pessoais (na pior das hipóteses, assim se espera, aprender alguma coisa para si)" (Ibid, 1998, p.15).Como exemplo, citamos alguns comentários das crianças durante o jogo Alfabeto Melado:

31 Esse jogo apresenta todas as letras do alfabeto, seguindo a sua ordem, na qual as crianças interagem fazendo o traço da letra na tela do tablet. Ao finalizar o traçado de cada letra o aplicativo fala oralmente o nome da letra, e mostra imagens de elementos (objetos, animais, comidas e etc) que iniciam com a letra abordada. 


\begin{abstract}
Harry Potter comenta com Pica-pau amarelo: "Nossa, $\mathrm{N}$ de noiva", e Picapau Amarelo responde sorrindo: "Eu tenho uma noiva". Soluço, durante um momento nesse mesmo jogo chama a professora da turma e fala: "Profe, apareceu a minha letra", se referindo a primeira letra do seu nome. (Relato da $1^{\mathrm{a}}$ intervenção com o $1^{\circ}$ ano $\mathrm{B}$ ).
\end{abstract}

A própria estrutura do jogo em si oferecia essas possibilidades de trocas entre as crianças, pois não apresentava tempo máximo para realização e nem desafios que exigissem ações imediatas, bem como não havia o risco de perder uma fase, pois o objetivo desse jogo era o de possibilitar ao jogador realizar o traçado das letras do alfabeto, respeitando seu ritmo e tempo. Na Figura 1 vemos as crianças jogando Alfabeto Melado.

Figura 1. Capitão Jack e Nicole jogando Alfabeto Melado.

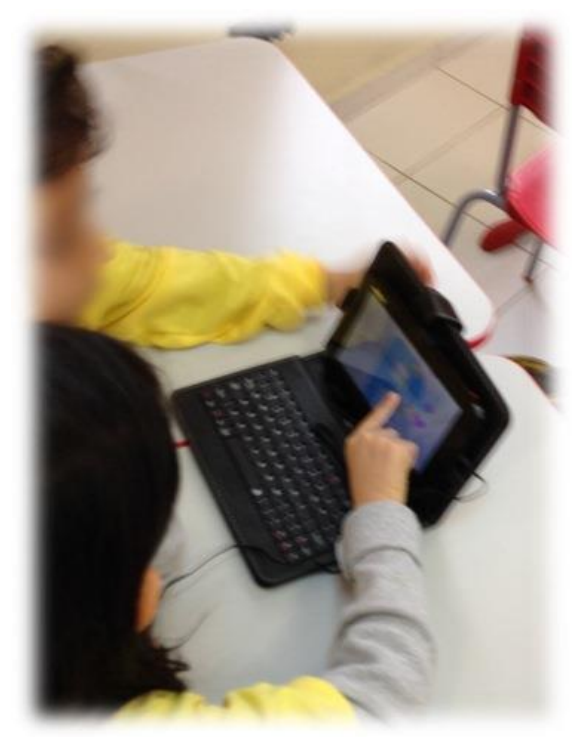

Fonte: Acervo das autoras, 2014

Nesse caso, consideramos que houve a presença de um estado colaborativo entre as crianças, que consiste numa perspectiva de que "[...] os participantes cooperariam em um processo e manteriam a colaboração como um estado", envolvendo, inclusive, "um conjunto de questões relacionadas à como esse estado é estabelecido, mantido e terminado." (BRNA, 1998, p. 12).

No jogo Corrida do Pinguim Pororo ${ }^{32}$, as crianças retiraram a capa com teclado para poder jogar, já que esse jogo exigia a movimentação do tablet. No entanto, como cada dupla utilizava um mesmo tablet, o fato de a criança precisar segurá-lo em suas mãos para jogar dificultou a visualização do (a) colega, mas não impediu o seu acompanhamento atento às ações do par durante o jogo. No intervalo entre uma fase e outra, as crianças conversavam rapidamente, negociando a vez de jogar: "Mônica pergunta para Bianca: Tá, e quem foi que perdeu? Foi eu

32 Esse jogo apresenta um cenário de elementos pertencentes ao habitat do pinguim, e outros que se fazem presentes apenas no ambiente do jogo. Para jogar a criança precisa guiar o pinguim Pororo, movimentando o tablet, e quando necessário tocar na tela para o pinguim pular, desviando-o dos obstáculos. 
né? Então, agora é tu!" (Relato da $1^{a}$ intervenção no $1^{\circ}$ ano C). A Figura 2registra um momento durante esse jogo.

Figura 2: Alice acompanhando as ações de Tuailaiti Esparco no Jogo Corrida do Pinguim Pororo.

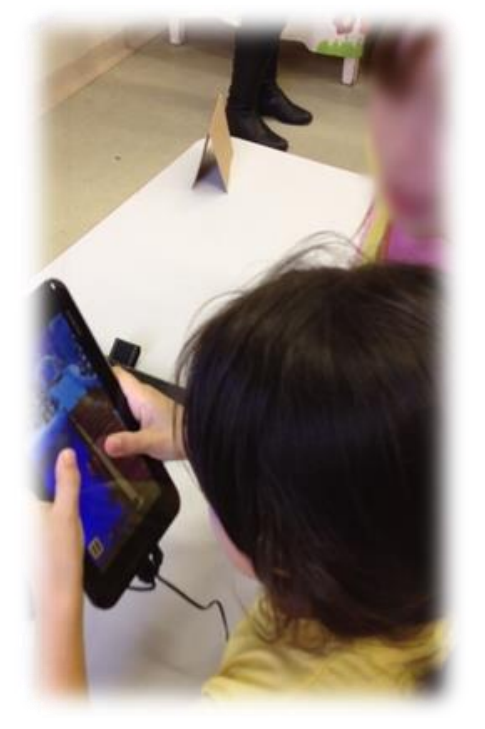

Fonte: Acervo das autoras, 2014.

Um fato que foi observado durante o uso desse jogo é o de que, por ele exigir um nível maior de concentração do usuário ao jogar para que o mesmo não perca a fase, as crianças interagiam menos umas com as outras, imergindo mais no mundo virtual e fictício do jogo. A partir desse caso, consideramos que não houve o estabelecimento da colaboração entre as crianças, pois cada uma tinha o objetivo de jogar a sua vez, independente da contribuição do colega para essa efetivação. Diante disso, de acordo com Brna (1998), essa colaboração nos parece ter sido firmada entre criança-sistema, na qual ambos colaboram na tentativa de elaborar um modelo a partir daquilo que o estudante sabe, o que justifica a imersão do jogador no ambiente digital.

Refletindo sobre isso, uma estratégia pedagógica para trabalhar a colaboração entre as crianças no uso de jogos eletrônicos é utilizar estilos que não apresentem limite de tempo ou que não exijam muito controle do usuário entre uma ação e outra, pois, quando esses fatores se fazem presentes no jogo, as crianças têm poucas oportunidades para conversar, estabelecer combinados e ajudar umas às outras, durante o processo, o que pode acabar individualizando as relações caso o objetivo inicial seja o de colaborar.

Para a professora do $1^{\circ}$ ano B, o fato de duas crianças usarem um mesmo tablet em jogos não é uma boa estratégia:

[...] talvez em uma pesquisa que a criança está acessando um dado da pesquisa, eu acho legal os dois olharem, mas quando é um jogo eu não acho bom. A criança que fica ali, fica meio inquieta, eu acho que não deve ser um tablet para duas crianças, principalmente, em jogos que elas ficam muito envolvidas. Quando se trata de uma pesquisa, um conteúdo, acho que o trabalho é tranquilo, inclusive ajuda para pesquisar, ainda mais nessa fase de 
alfabetização que eles não tem experiência pra localizar onde estão as informações. (Relato da entrevista com a professora do $1^{\circ}$ ano B).

Em relação aos momentos de sistematização das palavras no quadro, para rememoração do tema, percebemos diferentes situações de aprendizagem colaborativa, na qual as crianças auxiliavam umas às outras em suas dúvidas, como no momento em que falávamos sobre as características físicas dos pinguins e Maria Joaquina disse: "Ele tem narinas", e na sequência Elsa questiona: "O que é narinas"? Maria Joaquina responde apontando para o nariz: "É esses furinhos que a gente tem aqui". (Relato da $3^{a}$ intervenção no $1^{\circ}$ ano $\mathrm{C}$ ).

Esse caráter voluntário das crianças, de auxílio à solução de questões, é derivado do próprio processo de interação sobre um projeto comum, acarretando uma forma de aprendizagem colaborativa (LABORDE, 1996), por meio do nível da colaboração informal, conforme aborda Brna (1998, grifo nosso).

$\mathrm{Na}$ terceira intervenção, em que a proposta era a produção de uma videocarta, as professoras das turmas solicitaram que explorássemos um pouco mais o trabalho com jogos eletrônicos, tendo em vista que as crianças manifestaram ser essa atividade a sua preferida, pois sempre que nos viam andando pela escola elas nos questionavam se haveria mais joguinhos com o tablet. Inclusive, durante uma construção da pauta do $\mathrm{dia}^{33}$, uma das crianças questionou: "Hoje não vai ter jogo, profe"? Quando respondemos que, ao final de todas as atividades, se sobrasse tempo, eles jogariam, todos ficaram muito entusiasmados em saber da possibilidade. (Relato da $3^{\mathrm{a}}$ intervenção no $1^{\circ}$ ano B).

Durante os momentos de planejamento coletivo, as professoras salientaram a contribuição de jogos, como o do Alfabeto Melado, para auxiliar nesse processo de identificação das letras pelas crianças. Com base nisso, trouxemos o jogo Monta palavras, que tem um caráter pedagógico em relação à alfabetização, e o jogo Pilha de Pinguim, para continuar estabelecendo relação com o tema em questão.

Em outro momento dessa mesma intervenção, propusemos que, ao terminar a produção dos cartazes, por meio de desenhos e pinturas sobre a vida do pinguim, as crianças poderiam escolher um dos jogos já propostos. Com isso, o escolhido pela maioria foi o jogo Corrida do Pinguim Pororo.

Diante disso, um ponto importante a destacar foi a mudança do grau de interação estabelecido entre as crianças durante a realização desse mesmo jogo, com intenções e estratégias pedagógicas distintas, pensadas para atuação em diferentes momentos.

Na primeira intervenção, em que as crianças estavam organizadas em duplas para o uso de um tablet (2:1), ambas com diferentes níveis de desenvolvimento da escrita, elas acompanhavam o colega jogando, auxiliando-o com dicas, ou dizendo que já tinham passado por aquele momento do jogo, e até mesmo, para aguardar a sua vez de jogar. Já nessa terceira intervenção, em que cada criança estava com um tablet (1:1), cada uma estava

33 Atrelada a prática de alfabetização, na construção da pauta do dia as professoras das turmas em questão, costumavase trabalhar intensamente com as crianças as sílabas cantadas com palmas, buscando identificar a quantidade em números de sílabas e também de letras, presentes nas palavras, relacionando-as as atividades que seriam propostas em cada dia de aula. 
concentrada no seu jogo, imersa no ambiente virtual e nos desafios ali propostos. Logo, a interação social ficou prejudicada.

Portanto, consideramos que não é somente o conteúdo digital que pode individualizar as relações, a estratégia pedagógica planejada para o seu uso pode contribuir, tanto para colaborarem mais quanto para se individualizarem, pois "[...] se é dado a cada criança um dispositivo móvel, isso pode promover o trabalho por elas mesmas, enquanto, se compartilharem um, elas são obrigadas a colaborar mais". (ROGERS; PRICE, 2009, p. 05, tradução nossa).

Quando questionamos a professora do $1^{0}$ ano C, perguntando se ela considera que o tablet individualiza o processo de construção de conhecimentos, ela afirma que não, e complementa dizendo:

\begin{abstract}
[...] depende do encaminhamento que é feito, pois depende de como você vai propor o uso dessa tecnologia. Porque as crianças interagiam, pediam ajuda uma para a outra, mostravam, aí depende de você permitir isso para que essa interação ocorra. Eu acho até que, pelo contrário, eles até podem estar olhando tudo ali, mas logo eles já querem compartilhar. Fazem qualquer coisa e já querem mostrar, eles querem te contar, eles querem socializar. (Relato da entrevista com a professora do $1^{\circ}$ ano $\mathrm{C}$ ).
\end{abstract}

A professora do $1^{0}$ ano $\mathrm{B}$ considera necessário ter momentos destinados a tarefas mais individuais, como é o caso do uso de jogos, por exemplo, em que ela avalia que cada criança precisa utilizar um tablet para jogar, pois "[...] as ferramentas, muitas vezes, já têm um formato que acabam propiciando mais o individualismo, mas isso não impede de fazer uma proposta diferente quando se tem um objetivo proposto, pois não é a ferramenta que vai determinar isso". (Relato da entrevista com a professora do $1^{\circ}$ ano B).

Ainda com relação aos momentos coletivos e individuais durante as atividades, a professora complementa afirmando o seguinte:

\begin{abstract}
Tem momentos, em outras atividades, independente de ser com o tablet ou outras ferramentas, que é um pouco mais de reflexão individual e momentos de reflexão coletiva. Tudo depende da forma como se organiza o trabalho. Depende da metodologia do professor, pois o tabletnão é uma metodologia é uma ferramenta que pode estar inserida dentro de uma metodologia que vê esse trabalho mais coletivo ou que vê o aluno dentro de uma produção mais individual. (Relato da entrevista com a professora do $1^{\circ}$ ano $\mathrm{B}$ ).
\end{abstract}

Na visão da professora, a tecnologia é percebida como suporte à aprendizagem e, nesse caso, a individualização, que pode ser causada pela estratégia pedagógica articulada ao conteúdo e à forma de acesso, pode possibilitar a investigação do sujeito como aprendiz, inclusive, desse meio (CHURCHILL; CHURCHILL, 2008).

Ao realizar uma atividade mais individual o sujeito tem a possibilidade de se preparar para a atuação em grupo, tendo em vista a própria gênese social das funções psicológicas superiores apontadas por Vigostski (1995, p. 150), quando o autor afirma que "[...] toda função entra em cena duas vezes, em dois planos, primeiro no plano social e depois no psicológico, ao princípio entre os homens como categoria interpsíquica e logo no interior da criança como categoria intrapsíquica". 
Pautadas na perspectiva Vigotskiana (1996), consideramos que é nesse processo dialético construído de forma social e individual que o sujeito se constitui como ser histórico e social, lembrando que a interação social é uma das prerrogativas para o desenvolvimento humano.

No sentido de possibilitar às crianças a oportunidade de aprenderem e ensinarem umas às outras, numa relação de reciprocidade, planejamos, em diferentes momentos, práticas que pudessem promover a aprendizagem colaborativa.

Outro momento em que propusemos isso foi quando distribuímos os cartazes para confecção pelos grupos para o desenvolvimento da vídeo-carta ${ }^{34}$, e questionamos as crianças antes de iniciarem a produção, conforme o diálogo que segue: "Vocês sabem o que é um trabalho em equipe"? E Bela respondeu: "É fazer junto com o outro". Diante dessa resposta, enfatizamos a importância dos combinados no momento da produção dos desenhos e da conversa com os colegas para a espera da sua vez de pintar etc. (Relato da $3^{a}$ intervenção no 10 ano $B$ ).

Em relação ao que foi exposto, reafirmamos a importância desses momentos de mediação pedagógica, tendo em vista que essa atividade tinha a colaboração como objetivo final, já que a confecção para apresentação do cartaz era uma proposta a ser constituída pelos grupos em prol de um objetivo comum - a vídeo-carta.

Para a realização dessa atividade, fundamentamo-nos em Rogers e Price (2009), que indicam a contribuição de atividades de criação de conteúdos entre as crianças, pois, ao mesmo tempo em que aprendem a desenvolver suas narrativas para se expressar, elas também se manifestam por meio de diferentes formas de representação, sendo este mais um ganho com a atividade pensada e desenvolvida de forma coletiva.

Apesar do propósito inicial da atividade ser o da produção dos cartazes, em grupo, notamos que muitas crianças se individualizavam no processo em vez de interagir com os colegas.

Durante essa observação em uma das turmas, percebemos que as crianças de dois dos quatro grupos conseguiam trabalhar bem, juntas, conversando e negociando o que seria produzido, dividindo o que cada uma faria na construção do desenho. Já nos outros dois grupos, as crianças realizavam seus desenhos e pinturas de forma mais isolada, nos cantos da cartolina, realizando a tarefa, inclusive, de forma descontextualizada com relação ao desenho do restante do grupo e da temática em questão.

$\mathrm{Na}$ continuidade dessa mesma atividade, em outro dia de intervenção, após alguns momentos de mediação, percebemos uma diferença no nível de colaboração entre dois grupos do $1^{\circ}$ ano $\mathrm{B}$ durante a produção dos desenhos, conforme apresentamos na Figura 19 a seguir.

$34 \mathrm{Na}$ proposta de produção da vídeo-carta, uma turma apresentaria a outra, por meio de um vídeo, diferentes informações sobre o que aprenderam a respeito dos pinguins. 


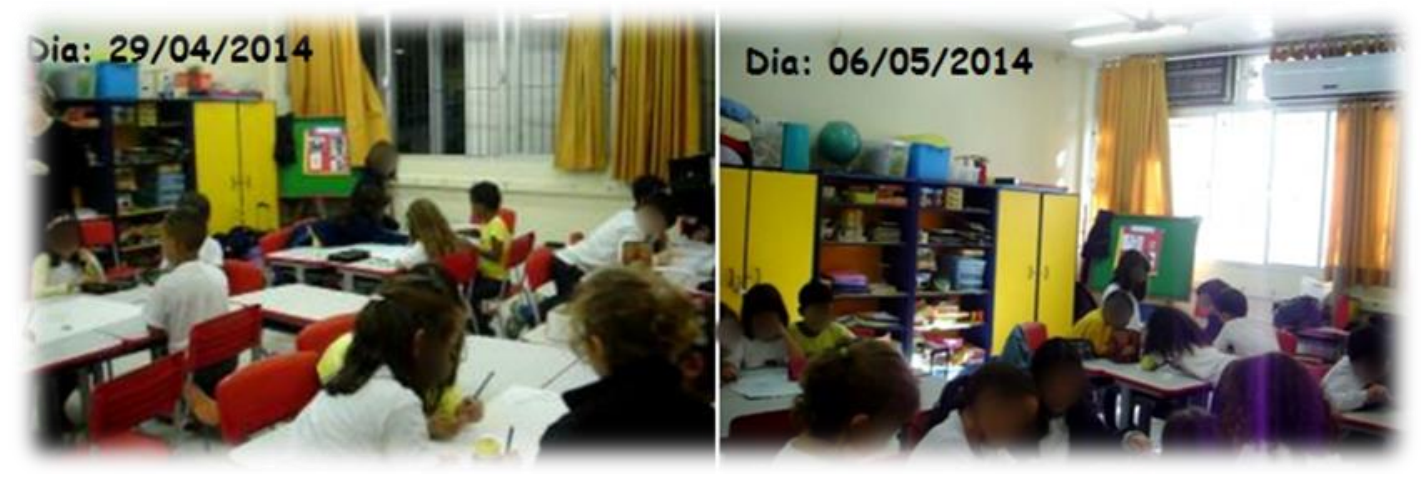

Fonte: Acervo pessoal, 2014.

Tendo em vista a situação apresentada, fundamentamo-nos em Brna (1998, p.15) quando afirma que "a divisão do trabalho pode ser parte da colaboração", e esta, por conseguinte, pode se configurar tanto um estado quanto um processo, a depender dos contratos implícitos e explícitos firmados.

A partir dessa atividade consideramos que as crianças tiveram a oportunidade de passar pelos seis níveis de colaboração abordados por Brna (1998), a saber: a divisão de tarefas; o estado de colaboração; a colaboração como propósito final; a colaboração como meio, e a colaboração tanto formal como informal.

Desse modo, destacamos que nossa mediação pedagógica foi fundamental para contribuir no desenvolvimento da colaboração nos grupos, fazendo com que as crianças estabelecessem uma relação de parceria entre elas, já que esta era uma das prerrogativas na qual se pautava a atividade em questão.

Essas mediações foram fundamentais ao processo de desenvolvimento das crianças, pois estimularam a criação de Zonas de Desenvolvimento Proximal, permitindo-nos "delinear o futuro imediato da criança e seu estado dinâmico de desenvolvimento, propiciando o acesso não somente ao que já foi atingido através do desenvolvimento, como também àquilo que está em processo de maturação". (VIGOTSKI, 1991, p. 98).

Ao questionar as crianças sobre suas preferências para a confecção dos cartazes, em relação à divisão de tarefas, a acordos coletivos ou à produção individual na elaboração dos desenhos, elas responderam:

"Desenhar sozinho porque ai a gente pode fazer tudo o que quiser, e não tem ninguém para dizer: "ah, não, eu não quero fazer isso"." (Elsa). "É porque, por exemplo, eu quero fazer um coração e a pessoa não quer que eu faça, aí ela fica brava comigo, por isso é melhor desenhar sozinho (Maria Joaquina). "É melhor combinar com o colega o que vai desenhar, porquê senão tu faz neve e ele vai ali e faz grama, por isso é melhor combinar" (TuailaitiEsparco). "É melhor combinar com o colega porque depois alguém quer fazer a mesma coisa que o outro aí podem combinar, e outro quer fazer outra coisa, mas pode combinar para fazer outra coisa ou deixar os dois" (Alice). "Porque aí não fica com a folha toda só pra você" (Jack 2). "Porque a gente tem companhia" (Sofia $1)$. 
Em relação a esses relatos, percebemos que as crianças preferiam não estabelecer um estado colaborativo com o outro, tendo em vista que uma das premissas para isso é a de "manter uma compreensão compartilhada do problema, o que implica que eles irão precisar discutir o estado dos seus progressos" (BRNA, 1998, p. 14), fato este que pareceu ser um incômodo para elas. As opiniões sobre essa questão foram diversas, uma vez que as crianças apresentavam pontos de vista diferentes. À medida que fomos realizando as intervenções, percebemos alguns avanços com relação às negociações e ao estabelecimento de combinados entre as crianças, principalmente durante as atividades planejadas com o uso de um tablet para cada dupla e/ou trio.

No entanto, ao indagarmos sobre a preferência de uso coletivo ou individual do tablet durante as atividades, elas responderam, em coro, que preferiam um para cada uma, e algumas justificaram sua resposta da seguinte maneira:

\begin{abstract}
"Porque aí a gente não precisava esperar a vez, porque dai a gente fazia o A e tinha que esperar o outro fazer B. Aí a gente poderia fazer tudo sozinho" (Elsa). Nisso a pesquisadora questiona: "Mas e se o jogo é difícil e a gente não consegue jogar sozinho?". E Elsa responde: "Aí complica", enquanto outra colega da turma faz um comentário: "Aí a gente pede ajuda para o amigo que tá na frente". "Porque ai uma pessoa não fica sozinho só com o tablet escolhendo o jogo dela, aí a outra não participa" (Jack 2). Violetta diz: "eu gosto mais é de jogar sozinha, porque aí eu não preciso ficar com otablet pra lá e vira uma confusão. Aí quando tu vai jogar, tu já perdeu o jogo". (Relatos das entrevistas coletivas com as crianças dos $1^{\circ}$ anos $B$ e C).
\end{abstract}

Percebemos, nessas falas, e na manifestação das crianças durante as intervenções, uma grande ansiedade para utilização do tablet, tendo em vista a novidade que ele representava naquele contexto.

Nas atividades de filmagem, fotografia e apresentação dos cartazes, as crianças também trabalharam no pressuposto da aprendizagem colaborativa apontado por Brna (1998), pois, nesse momento, houve uma divisão de tarefas em que cada um ficou responsável por uma ação durante a apresentação do cartaz. No entanto, todos estavam mobilizados por um projeto comum que era a vídeo-carta. Na Figura 4 a seguir apresentamos esse momento em um dos grupos. 
Figura 4. Crianças durante a apresentação do cartaz sobre o habitat do pinguim.

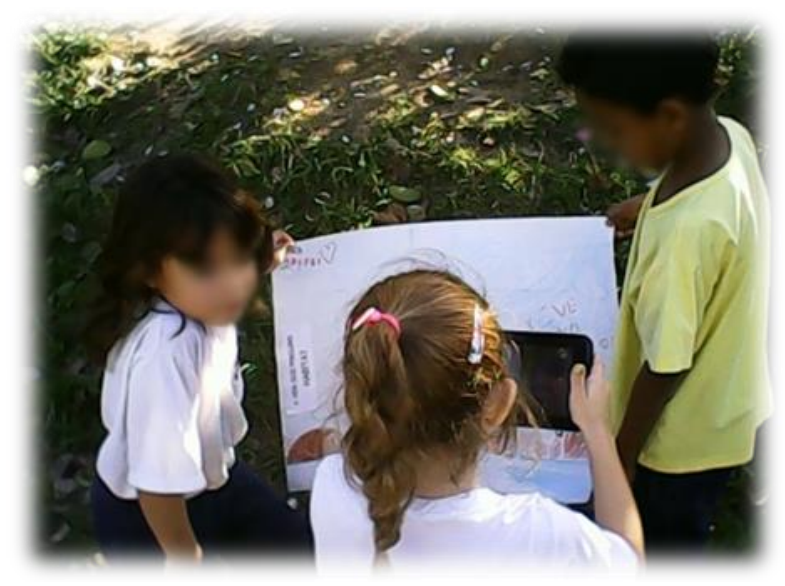

Fonte: Acervo pessoal, 2014.

Levando em consideração os dados obtidos em campo, avaliamos que o conteúdo a ser trabalhado de forma coletiva entre as crianças precisa oferecer uma estrutura que possibilite a colaboração e a troca de experiências durante o uso, caso contrário, isso pode individualizar as relações.

Entretanto, essa individualização não pode ser vista como ponto negativo para o processo de aprendizagem, porque, conforme Brna (1998), na aprendizagem colaborativa existem momentos de trabalho individual e em grupo, o que ainda caracteriza um estado de colaboração.

Diante disso, enfatizamos a importância do planejamento de estratégias pedagógicas para possibilitar o desenvolvimento da aprendizagem colaborativa, bem como a necessidade de considerar as diferentes mediações presentes em um processo educativo em sua totalidade.

\section{Considerações}

Os novos letramentos configuram-se como novos desafios a escola, pois supõe a aquisição de habilidades, a interação e a produção social impulsionadas muitas vezes por dispositivos digitais que convergem diferentes meios. Nosso estudo, desenvolvido com crianças ainda em processo de alfabetização, revelou que mesmo não dominando a linguagem escrita elas eram capazes de utilizar os tablets sem dificuldades, demonstrando um processo simultâneo de apropriação.

Os tablets oferecem diferentes recursos e possibilidades, como acesso a câmera fotográfica, a filmadora, a internet, aos editores de texto e imagens e uma infinidade de aplicativos, incluindo jogos. As intervenções realizadas combinaram o uso de diferentes recursos às distintas estratégias e modo de organização social, a partir do que foi possível visualizar diferentes níveis de colaboração.

Assim, conclui-se que há muitas possibilidades ao inserir o uso do tablet em sala de aula e que o uso dessa tecnologia por si não individualiza ou favorece a colaboração, mas sim a combinação entre o planejamento, os objetivos, as estratégias e a mediação pedagógica. 


\section{Referências}

BARDIN, L. Análise de conteúdo. Lisboa: Editora Edições, 1977.

BRNA, Paul. Modelos de colaboração. Revista Brasileira de Informática na Educação. Florianópolis. No 3. p. 9 - 15. setembro, 1998. Disponível em: <http://www.lbd.dcc.ufmg.br/colecoes/rbie/3/1/001.pdf >. Acesso em: 6 ago. 2015.

CHING, D. et al. Harnessing the Potential of Mobile Technologies for Children and Learning. In: DRUIN, Allison (Ed.). In: Mobile Technology for children. Designing for Interaction and Learning. USA: Morgan Kaufmann, 2009.

CHURCHILL, D.; CHURCHILL, N. Educational affordances of PDAs: A study of a teacher's exploration of this technology. Computer and Education, Volume 50, 1439-1450, 2008.

COLL, C; MONEREO, C. Psicologia da educação virtual: aprender e ensinar com as tecnologias da informação e comunicação. Tradução Naila Freita. Porto Alegre: Artmed, 2010.

FIELD, R. (2005). Favourable conditions for effective and efficient learning in a blended face-to-face/online method. Proceedingsof 2005.2 Disponivel <http://www.ascilite.org.au/conferences/brisbane05/blogs/proceedings/23_Field.pdf>. Acesso em: 12 dez. 2014.

GASKELL, George. Entrevistas individuais e grupais. In: BAUER, Martin W.; GASKELL, George (orgs.). Pesquisa qualitativa com texto: imagem e som: um manual prático. Tradução de Pedrinho A. Guareschi. 11. ed. Petrópolis, RJ: Vozes, 2013.

GODOY, Arilda S. A pesquisa qualitativa e sua utilização em administração de empresas. Revista de Administração de Empresas, 35(4), 65-71, 1995.

HATZIGIANNI, Maria; GREgORIADIS, Athanasios; FLEER, Marilyn. Computer use at schools and associations with social-emotional outcomes-A holistic approach.Findings from the longitudinal study of Australian Children.Computers \& Education, v. 95, p. 134-150, 2016.

FALLOON, Garry. What's the difference? Learning collaboratively using iPads in conventional classrooms. Computers\&Education, v. 84, p. 62-77, 2015.

FREIRE, Paulo. Pedagogia do Oprimido. 9. ed. Rio de Janeiro: Editora Paz e Terra, 1981.

LANKSHEAR, C; KNOBEL, M. Aprendizagem social e novas tecnologias. Comunicação \& Educação. No 1. Entrevista concedida à Richard Romancini, 2015. Disponível em: <http://www.revistas.usp.br/comueduc/article/viewFile/90085/96722>. Acessoem: 02 jun. 2015. 2006. New Literacies: everyday practices and classroom learning. Maidenhead: Open University Press,

LABORDE, Colette. Duas utilizações complementares da dimensão social nas situações de aprendizado da Matemática. In: GARNIER, Catherine; BEDNARZ, Nadine et al. Após Vygotsky e Piaget: perspectivas social e construtivista escola russa e ocidental. Porto Alegre: Artes Médicas, 1996.

MALHEIROS, Bruno T. Metodologia da pesquisa em educação. Rio de Janeiro: LTC, 2011.

RAMOS, Daniela Karine. Processos colaborativos mediados pela rede eletrônica: um estudo com alunos do ensino fundamental. 2005. 175 f. Dissertação (Mestrado em Educação) - Programa de Pós-Graduação em Educação, Centro de Ciências da Educação, Universidade Federal de Santa Catarina, Florianópolis, 2005.

ROGERS, Y.; PRICE, S.The role of mobile devices in facilitating collaborative inquiry in situ. In: KONG, Siu C. (Ed.). Research and practice in technology. Inhanced learning, Asia-Pacific Society for Computers in Education, 2008. 
How Mobile Technologies are Changing the Way Children Learn. In: DRUIN, Allison (Ed.). In: Mobile Technology for children. Designing for Interaction and Learning. USA: Morgan Kaufmann, 2009.

ROSATELli, M. C; SOUZA, P. C; ARRIADA, M. C; PETRY, P. G. Ambientes de Apoio a Aprendizagem Cooperativa. In: Edla Maria Faust Ramos; Marta Costa Rosatelli; Raul Sidney Wazlawick. (Orgs.). Informática na Escola: Um Olhar Multidisciplinar. 1. ed. Fortaleza: Editora da UFC, 2003, v. 1, p. 46-74.

SHORE, Rima. The power of pow! wham! Children, Digital Media \& Our Nation's Future. Three Challenges for the Coming Decade.New York: The Joan Ganz Cooney Center at Sesame Workshop, 2008. Disponível em: $<$ http://www.joanganzcooneycenter.org/wp-

content/uploads/2010/03/cooney_challenge_advance_1_.pdf>. Acesso em: 15 dez. 2014.

SOARES, Magda. Novas práticas de leitura e escrita: letramento na cibercultura. Educação \& Sociedade. Campinas, vol. 23, n. 81, p. 143-160, 2002. Disponível em: <http://www.scielo.br/pdf/es/v23n81/13935>. Acesso em: jun. 2014.

TURKLE, Sherry. Alone Together: Why We Expect More From Technology and Less From Each Other. New York, Basic Books, 2011

VIGOTSKI, L.S. Teoria e método em psicologia. São Paulo: Martins Fontes, 1996.

VYGOTSKY, Lev S. A formação social da mente: o desenvolvimento dos processos psicológicos superiores. Tradução José Cipolla Neto, Luis Silveira Menna Barreto, Solange Castro Afeche. 4. ed. São Paulo: Martins Fontes, 1991.

ZABALA, Antoni. A prática educativa: como ensinar. Porto Alegre: ArtMed, 1998.

Submetido para avaliação em 28 de março de 2016

Aprovado para publicação em 19 de outubro de 2016

\section{Ana Paula Knaul}

Programa de Pós-Graduação em Educação - Universidade Federal de Santa Catarina - UFSC, Brasil, anaknaul@gmail.com

\section{Daniela Karine Ramos Segundo}

Programa de Pós-Graduação em Educação - Universidade Federal de Santa Catarina - UFSC, Brasil, dadaniela@gmail.com 